\title{
"Gane usted y ayude a la Teletón": mecanismos neoliberales en la gestión del bienestar
}

\author{
"Gane usted y ayude a la Teletón": Neoliberal \\ Management of Social Well-being
}

Mónica Humeres (1) https://orcid.org/0000-0002-9555-035X

Universidad Alberto Hurtado, Chile,monicahumeresr@gmail.com

\begin{abstract}
This article argues that neoliberalism must also be understood from its impact on the cultural sphere, and thus it shows how governmentality functions in Chile by analyzing the case of a television program. Specifically, using a "thematic narrative analysis" and various archival sources from 1978 to the present, I examine transformations in the Chilean Teletón over time. The results are clustered into three 'moments' that I label sensitization, identification and action, which link a social problem with a specific way of feeling and acting. In this way, it demonstrates how the management of both individual and collective well-being is promoted through the neoliberal organization of society. Finally, the conclusions state that to this day the mediation and pedagogical role of television cannot be dismissed.
\end{abstract}

Key words: governmentality, well-being, neoliberalism, television, Telethon.

Resumen: Este artículo se funda en la idea de que el neoliberalismo debe ser comprendido también en la esfera cultural, por este motivo busca mostrar cómo funcionan los mecanismos de gubernamentalidad a través del análisis del caso de un programa de televisión. Mediante un Análisis Narrativo Temático y considerando archivos históricos desde 1978 hasta el presente, se estudió el caso de la Teletón chilena y sus transformaciones en el tiempo. Los resultados se presentan agrupados en tres "momentos": sensibilización, identificación y acción, los cuales vinculan un problema con una forma de sentir y actuar específica. De esta manera, se muestra cómo en el caso analizado se promueve una gestión del bienestar, individual y colectivo, por medio de una organización neoliberal de la sociedad. En las conclusiones se señala que, aun en la actualidad, el papel mediador y pedagógico de la televisión no debe ser desestimado.

Palabras clave: gubernamentalidad, bienestar, neoliberalismo, televisión, Teletón. 


\section{Introducción}

El fenómeno de la Teletón ${ }^{1}$ permanece llamativamente poco explorado en las ciencias sociales. A pesar de que este espectáculo es cada vez más cuestionado de forma social por su "solidaridad" de mercado y por la imagen que proyecta de las personas con discapacidad y el rechazo de estas (Ferrante, 2017; Humeres, 2017), continúa siendo una forma legítima de entretenimiento y "beneficencia". Por lo tanto, hacen falta más análisis metódicos que ayuden a comprender los mecanismos mediante los cuales la Teletón (ritual, campaña, dispositivo de gubernamentalidad) genera vínculos con la población. De este modo, este artículo² surge del interés por comprender cómo funciona este espectáculo, cuáles son las relaciones que genera con el público, para analizar los mecanismos históricos por medio de los cuales se ha arraigado en la sociedad chilena.

La Teletón tiene relevancia a nivel latinoamericano, pues es un modelo que se ha exportado a Brasil, Colombia, Costa Rica, Ecuador, El Salvador, Guatemala, Honduras, México, Nicaragua, Paraguay, Panamá, Perú, Uruguay y Venezuela, constituyéndose la Organización Internacional de Teletones (ORITEL). A pesar de que este producto cultural tomará formas específicas en cada sociedad, la Teletón chilena es un referente a nivel regional: la popularidad que históricamente ha logrado, su amplia cobertura mediática y las cantidades de dinero que recauda son superiores de manera considerable en Chile. Así, la versión chilena además de ser la precursora, cuenta con un equipo de comunicación especializado que asesora al resto de las versiones latinas (Fundación Teletón, 2013). De todos modos, al analizar la Teletón de Chile se busca proveer de un marco analítico que pueda ser usado como referencia o de comparación para otras versiones de la región.

La Teletón es un fenómeno con múltiples aristas; por lo tanto, al examinar una dimensión no se pueden ignorar las formas en que se fusionan la discapacidad, la infancia, la "solidaridad", el entretenimiento, su función de campaña de recaudación, su forma de filantropía neoliberal, sus estrategias de marketing y publicitarias, y también, o gracias a todo ello, su papel como plataforma política. Mientras discapacidad, discapacidad e infancia y

1 Este artículo hace referencia a la Teletón en tanto espectáculo de entretenimiento, por ello, el análisis no contempla los centros de rehabilitación ni su labor, que se han construido a posteriori con el mismo nombre.

2 Este trabajo fue posible gracias al financiamiento de la Beca de Magister en el Extranjero número 3926/2011 y Beca de Doctorado Nacional número 21140386/2014, ambas de la Comisión Nacional de Ciencia y Tecnología (Conicyt). Santiago, Chile. 
solidaridad neoliberal han sido estudiadas en Chile (Ferrante, 2017 y 2018 ; Gutiérrez, 2014; Humeres, 2017; Energici, 2014; Román et al., 2014), en este artículo he privilegiado profundizar, sin excluir del todo las otras dimensiones, en el aspecto político de la Teletón, es decir, como un dispositivo de gestión del bienestar social de la población.

El principal argumento de este artículo es que la Teletón tuvo una función particular en la difusión del neoliberalismo en la sociedad chilena, pues permitió que las reformas estructurales tuvieran un correlato cultural que acompañase el cambio de modelo social. De esta forma, mediante la publicidad y una variedad de técnicas de mercadeo y comunicación estratégica, se dieron a conocer las marcas, los empresarios y las nuevas instituciones privadas -y su funcionamiento- que liderarían la transformación neoliberal.

El segundo argumento de este trabajo destaca la característica coyuntural en la cual se insertó la Teletón; es decir, esta no fue inventada para cumplir esta función de difusión del neoliberalismo, sino que los productores del espectáculo supieron aprovechar una convergencia única para ejecutar su idea con éxito, al mismo tiempo que proporcionó una excelente mediación para introducir el nuevo modelo social. La Teletón chilena trascendió su influencia como espacio televisivo, logrando una raigambre en la cultura nacional tan profunda que tras cuarenta años aproximadamente (comenzó en 1978) continúa siendo exitosa.

El primer argumento (la Teletón y su difusión de un nuevo modelo social) será fundamentado mediante el análisis empírico del material audiovisual; después desarrollaré las características sociales e históricas que forjaron el escenario recién señalado. En primer lugar, el país estaba siendo golpeado por una violenta dictadura militar, la sociedad estaba polarizada en posiciones políticas y éticas irreconciliables, ante lo cual la Teletón fue propuesta por sus productores como un momento de "tregua" (Bontempi, 2012).

En segundo lugar, a pocos años de comenzar la dictadura se introdujeron reformas neoliberales que privatizaron también la salud. Este escenario condicionó a la capacidad de pago de cada individuo o familia el acceso a cualquier servicio médico. De este modo, la Teletón se instaló en Chile como una campaña de recaudación para niños "lisiados" y fue difundida como una obra social necesaria. En tercer lugar, estas transformaciones coincidieron con cambios tecnológicos relevantes, como la expansión de la televisión a todo el territorio nacional (Tagle, 2009). Dicha transformación le supuso un poder inusitado a la Junta Militar de Gobierno, la cual quedó en posición de transmitir sus mensajes unilaterales a gran parte de a la población de manera simultánea, mediante frecuentes cadenas nacionales de televisión (Correa et al., 
2001). Finalmente, la Teletón haría suyo el formato de cadenas nacionales televisivas, como ningún otro espectáculo televisivo lo había hecho hasta entonces y continúa siendo relevante para la cultura masiva.

Dentro de todas las aristas de análisis posible, en este trabajo se presta especial atención a la gestión del bienestar que la Teletón realiza. Así, el subtítulo de este artículo "mecanismos neoliberales de gestión del bienestar" hace referencia a una serie de pautas de acción que vincularon una recompensa individual con una social. Estos mecanismos son pormenorizados mediante el análisis de la Teletón como caso, donde el término bienestar se emplea en este artículo como un recurso para dar cuenta de algo que podría pensarse como contradictorio: neoliberalismo y bienestar. Tradicionalmente, los Estados de Bienestar han realizado una gestión estatal de las áreas que, desde el liberalismo clásico, se pensaban siempre al margen del mercado (Mirowski y Plehwe, 2009; Foucault, 2007).

La salud, la educación y la previsión, tal como sucedía en Chile predictadura, estaban organizadas por el Estado mediante fondos públicos. Por eso, cuando la Teletón invitó a "ganar" individualmente a través del consumo - como sugiere el título "Gane usted y ayude”-, se comenzó a difundir una nueva cultura y modo de resolver las cuestiones sociales (lo que antes, en el modelo socialista pre-dictatorial era el bienestar). Obtener placer comprando y al mismo tiempo "ayudar" a los niños con discapacidad como parte del objetivo nacional, propuso un doble juego de individualizar la desigualdad social, por un lado, y colectivizar la ayuda de manera conspicua, por otro. Esta forma de gubernamentalidad, como se detalla más adelante, ha tenido un éxito considerable en una parte importante de la sociedad.

En consecuencia, el análisis de la Teletón es también un análisis de los modos de operar del neoliberalismo o bien, de mecanismos de gubernamentalidad (Foucault, 2007; Rose, 1993; Lemke, 2012). En el caso de Chile, a pesar de la violencia del autoritarismo con la cual se impuso el neoliberalismo, así como el arraigo constitucional de este modelo implementado por el grupo de los llamados gremialistas (Fischer y Serra, 2004), es necesario también comprender lo que sucedió en el ámbito cultural. De esta manera, argumentaré que los medios de comunicación, en especial la televisión, tuvieron un papel privilegiado para modificar la cultura en los años setenta. Asimismo, contraviniendo el aclamado declive actual de la televisión tradicional, sostengo que la televisión sigue teniendo un papel preponderante para modelar la cultura masiva.

El presente artículo se realizó considerando tres perspectivas teóricas. Por una parte, apunto a contribuir con un ejemplo específico y acotado a 
los debates sociológicos de las justificaciones que produce el capitalismo (Weber, 2001; Boltanski y Chiapello, 2002). Por otra parte, con base en las particularidades del neoliberalismo, el artículo discute ciertos mecanismos de gubernamentalidad (Rose y Miller, 1992; Brady, 2016; Lemke, 2012; Fougère, 2010) y, por último, pretende aportar a los análisis sobre el lugar de la televisión y, en particular, de la Teletón en las sociedades latinoamericanas.

$\mathrm{El}$ argumento se desarrolla en cuatro partes. En primer lugar se presenta el caso de la Teletón chilena junto a la coyuntura política y social particular en la que se formó, al mismo tiempo que se describe el lugar que ha tenido, y aún ocupa, en la cultura nacional. En segundo lugar se expone una discusión teórica en la cual se inscribe el análisis, principalmente, estudios sociológicos del neoliberalismo, de la gubernamentalidad y algunas perspectivas analíticas de la comunicación. En tercer lugar se detallan algunas características del Análisis Narrativo Temático (Riessman, 2008). Finalmente, los resultados se presentan agrupados tres "momentos": sensibilización, identificación y acción, los cuales vinculan un problema con una forma de sentir y actuar específica.

\section{La Teletón Chilena}

En Chile, la Teletón es un espectáculo televisivo de larga duración (27 horas ininterrumpidas) y con cobertura nacional, que se repite todos los fines de año desde 1978 hasta la actualidad. Este "telemaratón" funciona como campaña de recolección de fondos para niños con discapacidad, donde los aportes se hacen comprando los productos de las marcas que se indican en el espectáculo. El alcance comunicacional de la Teletón es enorme: al transmitirse en cadena nacional (en donde participan todos los canales de la Asociación Nacional de Televisión de Chile), ocupa un lugar privilegiado dentro de los medios de comunicación y en la sociedad, produciendo un ambiente que solo es comparable al de los mensajes presidenciales que se transmiten de este modo.

Además, el acompañamiento comunicacional opera en los más variados formatos: diversas radios nacionales transmiten en directo el programa sumándose a la cadena; varias comunas ceden espacios publicitarios en la vía pública; los periódicos y revistas cubren el evento; asisten las autoridades políticas. Por ello, muchos profesionales de la comunicación, animadores, actores y actrices, periodistas, o figuras públicas como deportistas populares o políticos, se disputan ser parte del espectáculo. 
Sin embargo, la Teletón es mucho más que una campaña de recaudación y un fenómeno televisivo, pues tiene un correlato que genera múltiples prácticas por parte de la población. Por ejemplo, miles de chilenos cambian el comportamiento de su consumo para "ayudar"; otros pintan sus automóviles con la palabra "Teletón” acompañada de un corazón y la fecha del espectáculo; cien mil personas acuden al Estadio Nacional para el cierre de la campaña; muchos se reúnen; algunos, incluso, sacan los televisores a la calle para pasar la noche en grupos mirando el espectáculo; existen además alcancías corporativas que se instalan en diversos espacios públicos y privados, entre otras prácticas.

Por lo tanto, no es aventurado afirmar que la Teletón es parte importante de la cultura e identidad chilena, ya que prácticamente el 100\% de la población la conoce, y la gran mayoría de la población la sitúa al nivel de otros símbolos nacionales, como la bandera, la cueca (baile nacional) o el equipo de fútbol nacional (Cuevas, 2008).

En la Cuarta Encuesta Nacional de Opinión Pública (ICSO-UDP, 2008), 70\% de las personas declararon que conocían y le gustaba la Teletón; $28 \%$ reconoció conocerla pero que no le gustaba; solo $0,4 \%$ declaró no conocerla (ICSO-UDP, 2008). Así también, la Teletón es una de las marcas con más prestigio a nivel nacional. En 2013, esta fue elegida dentro de las tres mejores marcas del año por los expertos en la materia (Grandes Marcas, 2019). La Fundación Teletón reconoce con orgullo que con su trabajo continuamente mejora la imagen de marca de sus socios estratégicos, pues "la rehabilitación no solo es física, sino también emocional” (Teletón, 2019) de todos los chilenos. La respuesta social que genera este fenómeno es considerable y no se le puede reducir a solo un hábil método para vender a costa de la imagen de los niños con discapacidad.

\section{Sociología, neoliberalismo y comunicación}

La pregunta por los modos de operar del capitalismo y los respectivos cambios sociales que produce han sido asunto de interés para las ciencias sociales desde sus inicios y tiene expresiones en las tradiciones intelectuales más significativas del siglo XIX y XX. Ya desde Weber (2001) en adelante, los sociólogos han intentado descifrar y comprender cómo los cambios en el pensamiento económico y político permean en las distintas sociedades. Algunos herederos de Weber, como Boltanski y Chiapello (2002) sostienen que el capitalismo requiere de una justificación para que los individuos se adhieran a este, pues se necesita el accionar de muchas voluntades para 
funcionar. Boltanski y Chiapello (2002) argumentan que el dinero o las recompensas económicas no lo justifican todo y por ello se requiere un sentido para la acción. Tal como lo dijo Weber (2001), es necesario un espíritu o ideología que justifique la adhesión al capitalismo.

No obstante, Boltanski y Chiapello (2002) matizan la tesis de Weber. Según explican, no es posible que lo único relevante para que las personas se adhieran al capitalismo sea proporcionar justificaciones a nivel individual. Tal como Hirschman (1977), quien argumenta que las justificaciones que apuntan al bien común son más efectivas, Boltanski y Chiapello (2002) proponen que el sustento del capitalismo se basa en una compaginación de las justificaciones tanto individuales como de las que apuntan al bien común para guiar la acción. El análisis de las justificaciones en el capitalismo es un tema relevante para la sociología, que busca el papel creativo del capitalismo.

Esta mirada se condice con una analítica del poder, como la propuesta por Foucault (2003), en la cual se comprende que el poder meramente negativo es incapaz de producir algo; sería una especie de antienergía. No basta con reprimir y obligar, pues el poder más efectivo se ejerce desde la energía creativa. De este modo, si es necesario seducir para persuadir (una máxima básica de los estudios de comunicación), también deben ser comprendidas las características persuasivas del capitalismo, o específicamente de su versión neoliberal, como sus justificaciones o lo que otros han llamado ideología o espíritu.

Chile ha sido señalado por muchos como un caso ejemplar de instalación del neoliberalismo, pues -como es de amplio conocimiento- este país "fue un escenario temprano de experimentación intensiva con neoliberalismo aplicado durante períodos prolongados" (Plehwe, 2009: 32). Existen pocas (o ninguna) dudas sobre las conexiones de las políticas neoliberales instaladas en Chile. Desde la perspectiva de Dean (2014), Chile es el caso por excelencia mediante el cual se puede restituir empíricamente la influencia del neoliberalismo en el individuo y las organizaciones.

El neoliberalismo chileno ha sido objeto de análisis a nivel internacional (Klein, 2007; Harvey, 2005) y nacional (Valdés, 1995; Silva, 1995; Fischer y Serra 2004; Ffrench-Davies, 2003; Cavallo, 1989; Garate, 2012; Undurraga, 2014; Guzmán et al., 2017). Asimismo, los vínculos entre el régimen de Pinochet y la Escuela de Economía de Chicago son bastante conocidos y estudiados. 


\section{Estudios de gubernamentalidad y sus limitaciones}

Por otro lado, desde los años noventa, en las ciencias sociales surgieron los estudios de gubernamentalidad, como un marco analítico para problematizar las formas de gobierno contemporáneas, las cuales involucran estrategias y relaciones de poder, que se ejercen tanto dentro como fuera del Estado (Rose y Miller 1992; Brady 2016). Junto a ello, y tal como señala Lemke (2012) al integrar formas de conocimiento, estrategias de poder y tecnologías del yo, esta perspectiva ha hecho posible dar una explicación más completa de las transformaciones sociales y políticas en su desenvolvimiento.

Sin embargo, esta línea analítica de corte eurocentrista (Lemke, 2012) debe ser complementada con una perspectiva que permita pensar de manera más precisa las especificidades de los países latinoamericanos. Después de todo, no es lo mismo una sociedad neoliberal latinoamericana que una sociedad neoliberal pos Estado de Bienestar europea, como tampoco sus mecanismos de gubernamentalidad.

En la tarea de dar cuenta de la complejidad que convive en las formas de gobierno contemporáneas, generalmente los académicos hacen referencia al arte de gobierno o conducta de la conducta - como señalara Foucault (2007) en sus cursos del Collège de France- de sociedades "liberales avanzadas". Esta última denominación hace referencia a la capacidad de gobernar "a través de las elecciones reguladas de los ciudadanos individuales" (Rose, 1993: 285). Así también "el liberalismo difiere de otras racionalidades de gobierno notablemente porque considera la necesidad de la gente de no sentirse gobernada: significa gobernar gente libre" (Fougère, 2010: 427). Esta acepción sirve para emplazar algunos problemas actuales de los estudios de gubernamentalidad.

Por otra parte, desde hace tiempo el concepto de neoliberalismo ha sido revisado por varios académicos, quienes acusaban que este se estaba convirtiendo en una metanarrativa (Peck et al., 2010), y por lo general se usaba sin la necesidad de definirlo (Thorsen, 2010). De la misma manera, se decía que, a menudo, el neoliberalismo caracterizaba una variedad excesivamente amplia de fenómenos (Boas y Gans-Morse, 2009) muchas veces de modo exagerado (Dean, 2014). Plehwe (2009) argumentó que la ambigüedad y el uso excesivo, así como la complejidad de definir el neoliberalismo, han contribuido a que a muchas veces el neoliberalismo parezca un invento exagerado de la izquierda. En esta misma dirección, Flew (2014) mostró que mientras el término neoliberalismo era escasamente empleado antes de los años noventa, este fue experimentando un aumento exponencial en el tiempo. En las décadas recientes, esta tendencia ha continuado e incluso 
se ha intensificado, en buena parte como efecto de la crisis financiera "global" de 2008 y la consecuente búsqueda de los cientistas sociales para proveer explicaciones (Lee, 2008).

En este artículo me interesa comprender el neoliberalismo desde una acepción acotada, como la que realiza Mirowski y Plehwe (2009), en específico Mirowski (2009) y Foucault (2007). Para efectos de este análisis, no desarrollaré esa definición a profundidad, que puede encontrarse en las publicaciones recién referidas, sino señalaré que al contrario del liberalismo, el neoliberalismo en tanto "pensamiento colectivo" (Mirowski, 2009) necesita de un Estado activo que promueva y articule la expansión del mercado a todas las áreas de la vida. Gane (2014) señala que el neoliberalismo surge de la búsqueda de una ciencia social alternativa, capaz de establecer el cálculo racional monetario como principio válido para la acción en todas las esferas de la vida. Como señala Mirowski (2009: 427), "sería un error considerar que el neoliberalismo se encuentra estrechamente dentro del ámbito de la historia de la economía como tal". Por ello, resulta trascendental comprender el neoliberalismo no como una teoría económica, sino como una teoría/ proyecto social.

Por otro lado, las formas de solidaridad neoliberal han sido analizadas en Chile por Energici (2014) como una forma de gubernamentalidad contemporánea ampliamente extendida. En esta misma línea, Román-Brugnoli et al. (2014) han demostrado cómo la solidaridad se ha vinculado con fuerza hacia el ámbito de las emociones, y la identidad nacional al alero del neoliberalismo, dejando atrás la relación anterior entre solidaridad con los derechos sociales. Por su parte, Ferrante (2018b) ha evidenciado cómo ciertas prácticas de mendicidad hacia personas con discapacidad están fuertemente asociadas a una idea de solidaridad en Chile, menoscabando la instalación efectiva de un enfoque de derechos.

También Ferrante (2017 y 2018a) ha analizado esta construcción caritativa de la solidaridad en torno a la discapacidad a partir de la Teletón y su arraigo en Chile. Finalmente, se ha señalado que la triple vulnerabilidad de los niños (infancia, discapacidad y pobreza) se usa en la Teletón para sensibilizar a la población apelando a la solidaridad (Humeres, 2017). En suma, discapacidad, "solidaridad neoliberal" o caridad e identidad tienen un vínculo estrecho en Chile. Más adelante se apreciará en detalle cómo se produce esa relación. 


\section{Televisión y mediación social}

En el caso del medio que aquí se analiza, la televisión (especialmente en las décadas de 1970 y 1980 en Chile), como toda tecnología en uso, tiene características situadas. Martín Serrano (2008: 115) analiza la televisión como medio desde un punto de vista histórico y la define como una "máquina técnica que produce objetos culturales". No obstante, la televisión produce pero también reproduce la cultura. El investigador demuestra cómo el control se ejerce a través de los códigos de manera implícita: en la televisión se pretende ocultar "la existencia de un emisor que controla la información" (Martín-Serrano, 2008: 133), lo cual es observable en la pretensión de los medios informativos de transmitir una "verdad objetiva". Parte de esta potencialidad de la televisión de ejercer un control más sutil que en otros medios estaría dada por su característica de medio index (Martín-Serrano, 2008). Mediante los códigos se pretende reproducir el sistema normativo de la sociedad, al tiempo que se indexan imágenes o situaciones a determinados discursos e interpretaciones.

De este modo, las cualidades de la televisión como medio index y su lugar en la cultura dan cuenta de un mecanismo de gubernamentalidad, que produce significaciones de manera implícita. No obstante, el poder de la televisión tiene sus límites. El modelo de la aguja hipodérmica (Lasswell, 1927), en el cual se pensaba que la audiencia obedecía ciegamente a los efectos esperados por los productores comunicacionales, está obsoleto desde hace bastante tiempo. Los estudios culturales han sido especialmente productivos en elaborar un marco que permita comprender la complejidad y multidireccionalidad de la comunicación y su audiencia. Se ha insistido en que la decodificación del mensaje por parte de los receptores era tan importante como el diseño de este en la significación final. Hall (1973), uno de los máximos exponentes de esta visión, se refería al circuito del diseño/recepción como encoding (codificando) y decoding (decodificando); es decir, si los diseñadores encriptan mensajes o guiones, los receptores o usuarios reinterpretan esas direcciones en su uso.

\section{La televisión chilena durante la dictadura militar}

Tal como afirma Leighton (2012), el golpe de Estado comenzó con la toma de los medios de comunicación, y su estricto control se mantuvo durante toda la dictadura de Augusto Pinochet. Correa et al. (2001) han expresado que la televisión fue el medio de comunicación más controlado por la 
dictadura militar, siendo empleada para difundir los nuevos valores de la sociedad que se estaba fundando: "Al fin y al cabo, la televisión devino en fuerza propulsora de las dinámicas de mercado, ayudando a instaurar los patrones culturales que alientan el desarrollo del capitalismo sustentado en la propensión al consumo" (Correa et al., 2001: 306-307). Asimismo, la Junta Militar se sirvió de las cadenas nacionales obligatorias: una transmisión simultánea que cubría todos los medios de comunicación en directo, tanto los canales de televisión como las emisoras radiales, alcanzando una cobertura sin parangón hasta el momento (Tagle, 2009).

A la par, en este periodo, convergió el cambio tecnológico (ocurrido en 1976), donde se implementó la televisión satelital consiguiéndose la cobertura de señal en todo el territorio nacional, al mismo tiempo que aumentaba el número de televisores (Sierra, 2006). Es decir, el poder autoritario de la dictadura militar sumado a la expansión de la cobertura televisiva, generaron un enorme poder de difusión, que en 1978 fue aprovechado hábilmente por los productores de la Teletón.

\section{Metodología}

Los argumentos teórico-conceptuales antes expuestos están directamente vinculados con un Análisis Narrativo Temático (Riessman, 2008), de alrededor de cien piezas comunicacionales de la Teletón. En este destaca su cualidad de dar cuenta del contenido de lo dicho, donde el investigador considera ciertas teorías y, de este modo, dirige el análisis hacia sus objetivos. Las narraciones son interpretadas con base en la unicidad que conforman, y no en pequeños fragmentos o categorías. El Análisis Narrativo sirve para estudiar cómo diversas historias funcionan socialmente para movilizar a ciertos individuos o colectivos, o bien, para crear las posibilidades para que ciertos grupos generen pertenencia y participen de la acción. Un cualidad significativa del Análisis Narrativo Temático consiste en conservar las secuencias (en vez de codificar segmentos temáticos), con la finalidad de mantener el curso de la historia.

En el análisis se incluyeron los afiches publicitarios oficiales desde 1978 y hasta 2014, la totalidad de las canciones, llamadas "himnos"3 de la Teletón, desde 1979 y hasta 2014, y algunas campañas publicitarias. También se consideraron las historias de vida de los "niños símbolos", con las cuales comienza el espectáculo cada año. Los relatos de los principales productores de la Teletón y discursos institucionales complementaron la investigación.

3 Composiciones musicales acompañadas de videoclips que se producen cada año. 
Ya que este espectáculo no rompe los vínculos, sino que se produce gracias a todo lo que le rodea, como el contexto social y político, las referencias históricas se van incorporando en el análisis a medida que es necesario.

\section{Análisis}

La Teletón llegó a Chile en 1978 como un programa de larga duración que se popularizó bajo la conducción de Jerry Lewis en 1966, en Estados Unidos, bajo la promesa de ser un programa en beneficencia para los niños con distrofia muscular. Fue Mario Kreutzberger, conocido en Chile y en los países de habla hispana como don Francisco, ${ }^{4}$ quien, luego de observar este formato en Estados Unidos, lo importó a Chile en 1978, convirtiendo la Telethon de Lewis en la Teletón. Tal como Lewis, Kreutzberger implementó un espectáculo donde se utiliza a niños con discapacidad para conmover y hacer publicidad de ciertas empresas comerciales, orientando el consumo como una forma de "ayudar".

No obstante, el impulso personal de Kreutzberger no hubiese tenido resultados sin una coyuntura favorable. Según cuenta la historia oficial, la Teletón surgió como una idea de Kreutzberger para unir al país polarizado y dividido de fines de los años setenta, donde surgió "la posibilidad de no sólo hacer una campaña para los discapacitados sino que también para unir al país" (Casarejos, en Bontempi, 2012). Tal como lo han demostrado otros análisis sobre el entretenimiento y la televisión en dictadura (Durán, 2012), una propuesta como la de Kreutzberger no podría haber sido más idónea para ese momento. Más allá del relato que ensalza la figura de un innovador visionario (Kreutzberger), el surgimiento de la Teletón se entiende mejor considerando la suma de factores coyunturales.

El llamado a la unidad "sin distingos políticos" (Fundación Teletón, 2013) continuó reafirmándose en los años noventa, y se mantiene en la actualidad como una de sus promesas de aparente neutralidad, como si no fomentase un modelo social por sobre otro. Asimismo, esa supervivencia se sostiene sobre una inquietante, sin duda hábil, mezcla de continuidad y cambio. Por una parte, la estructura general del espectáculo televisivo ha sido siempre similar: primero se presentan las historias de niños con discapacidad, mediante un lenguaje audiovisual que invita a la conmoción, y más adelante, diversas empresas, personificadas en el escenario por sus directores o representantes

4 En este artículo se usa tanto el apellido del animador (Kreutzberger) como su nombre de fantasía (don Francisco), dependiendo de si la referencia es al individuo o al personaje televisivo. 
comerciales, compiten por entregar el cheque más abultado. Ciertamente, en las 27 horas que dura el espectáculo pasan muchas cosas más -secciones de deporte, humor, vedettes y, por supuesto, avisos comerciales-; sin embargo, el argumento central del espectáculo se basa en la situación trágica de los niños y la superación de este desamparo mediante el aporte económico de empresas. Por otra parte, y como se pormenoriza más adelante, el lenguaje audiovisual se ha ido adaptando a las modas de cada momento.

A modo de exponer el argumento, adoptaré un modelo de explicación por momentos, tomado de los estudios de Ciencia, Tecnología y Sociedad (CTS), más precisamente de los estudios de la ciencia (Callon, 1986), infraestructuras (Ureta, 2015) y políticas públicas (Hamilton, 2011). Mediante la exposición del momento, lo que se busca no es un modelo acabado de algo que empieza y termina, sino una cristalización de lo que en realidad es un proceso (Hamilton, 2011). Asimismo, los momentos no son puros, sino que se superponen o complementan. Con todo, la expresión del momento permite observar un mecanismo o estrategia particular, capaz de activarse o no en distintos instantes. Por medio de las fases sensibilización, identificación y acción se describirán los modos de operar, que son tan discursivos como materiales.

\section{Sensibilización}

“Acompáñenos en esta cruzada de amor, que se llama Teletón”, así comenzaba la primera edición en 1978, con un coro celestial de fondo. La primera parte del espectáculo está fuertemente orientada a sensibilizar con lo que se supone es la descripción unívoca de la vida de los niños con discapacidad. Una pieza clave en la constitución del clima emocional que propicia la Teletón desde su obertura son las historias de vida de los "niños símbolo", con las cuales empieza cada edición. En esta versión de 1978, la historia se divide en tres tiempos: primero un clima trágico donde el niño o la niña vivía sin conocer la Teletón (música lenta y voces sombrías); luego se narra cuando conoce la Teletón, la pantalla se llena de colores y de tonos musicales alegres. En este discurso, lo niños con discapacidad de Chile deben ser luchadores, su problema se enfoca como una tragedia individual de la cual deben salir por su propia voluntad, deben caminar, deben hacer todo lo que un niño "normal" realiza. Finalmente, cuando aparece en escena la Teletón, en la historia se presentan mejoras en la vida del pequeño y de su familia completa.

Por ejemplo, en 1978, tras el corte de la pieza audiovisual, la cámara enfoca de cerca a un público altamente conmovido, sobre todo rostros 
de mujeres bañados en lágrimas, cubriéndose la cara con las manos; cientos de personas que no pueden contener su turbación. Este clima emocional se apuntala de manera constante durante las 27 horas, y los camarógrafos aprovechan prolijamente los primerísimos primeros planos: un par de ojos cubre toda la pantalla para exacerbar el efecto. En el cierre de la primera Teletón, que marcó la pauta de un lenguaje que aún continúa, aparece iluminada una silla de ruedas en el centro de un fondo negro; la luz se va ampliando hasta que surge la multitud ovacionando. El espectáculo concluyó con un conmocionado don Francisco, de rodillas, apoyando su mejilla y su nariz en el rostro del "niño símbolo".

$\mathrm{Al}$ observar el conjunto de piezas comunicacionales referentes a los niños con discapacidad (en especial las historias de vida, himnos y afiches oficiales), se evidencia que la construcción de la discapacidad como una tragedia individual se emplea como uno de los principales elementos sensibilizadores, que, supuestamente, representa a las personas con discapacidad infantilizadas. ${ }^{5}$ Por ejemplo, el himno de 1980 versaba: [Voz de niño] "Déjame creer que puedo ser feliz, dame una razón para vivir. Solo un pedacito y nada más, de todo tu corazón (Himno "De pie en la esperanza"). La sensibilización es una de las estrategias declaradas del equipo de producción (Fundación Teletón, 2013) para motivar la participación. Al margen de esto, la sensibilización tiene muchas formas posibles, y en ese repertorio los productores eligen la dramatización de la vida de un niño pequeño. ${ }^{6}$

Si, tal como plantea Illouz (2007), las emociones son significados culturales y relaciones sociales, tras 40 años (al 2018) de repetir este mismo discurso, existe una sociedad que ha aprendido a sentir y responder a dicho repertorio.

\section{Identificación}

La identidad nacional se ha ido trabajando de acuerdo con cada época en este espectáculo. Por ejemplo, a partir de 1998, año en que Chile participó en el Mundial de Futbol, las banderas, canciones, colores y símbolos patrios abundan cada vez en mayor cantidad. El equipo de la selección nacional

5 En 2004 se realizó el Primer Estudio Nacional de la Discapacidad en Chile (Zondek et al., 2004), donde se señala que la mayoría de las personas con discapacidad son adultos; solo $5,7 \%$ son niños de entre 0 y 14 años. Sin embargo, en la Teletón la discapacidad es sinónimo de niñez.

6 Tal como he señalado, esta visión trágica puede ser revisada en extenso en otros trabajos (Humeres, 2017), así como el rechazo de quienes alguna vez fueron protagonistas. 
fue clasificado y todo parece indicar que los organizadores de la Teletón aprovecharon la coyuntura de "unión nacional" que se vivía en ese momento. En ese año, de hecho, se adaptó una canción que se había creado para la barra de la selección nacional de futbol y se coreó en el Estadio Nacional: "Chileno, chileno, chileno de corazón identifícate con Teletón, chileno de corazón” (himno 1998: “Chile se identifica con la Teletón”). Así se re-afirmó el "desafío" anual de los chilenos, pseudo-deportivo, pero donde todos ganan.

Tal como se observa, la identidad nacional está al centro de la estrategia motivacional, apoyada en un discurso de la unidad, de un Chile un comprometido, solidario, generoso; por ejemplo: "Chile tiene corazón" o "demostrando nuestra fuerza nuestra unión" (himno 1996: "Otro paso adelante"). Ese sentir nacional que evoca la Teletón, destaca el uso de los símbolos nacionales, como la bandera nacional, la cueca (baile nacional), las canciones de barras futboleras y aclamaciones como: "Vamos chilenos".

En la búsqueda de lo nacional, el himno de 2003 comienza con una imitación del ritual mapuche, ${ }^{7}$ y a través de sus instrumentos típicos como la pifilca y el kultrún se simula una rogativa que versa: "Dame tu mano, ponte de pie ¡acuérdate!" (himno 2003: "Teletón es tuya”). Por otra parte, se promueve la idea de que ayudar te hace bien. Así se ilustra la idea en la canción: "Si sientes que te duele la tristeza, y estás cansado de esperar, abre las puertas de tu corazón y sentirás la alegría que entrega el amor" (todas las canciones son interpretadas por los cantantes más populares del momento). "Todo un país recibe dando" es una frase que da cuenta de la posible gratificación emocional o recompensa en las identidades de quienes participan.

En los últimos tiempos, y empleando a los artistas de moda, el tono comunicacional se ha ido tornando cada vez más "alegre": "Sale cada día un nuevo sol, siempre todo puede estar mejor, solo hay que pensar que todo va a estar bien y siempre sonreír chilenos y ser positivo desde el alma, siento felicidad cuando veo que estamos unidos "(Con la fuerza del corazón, 2011).

La unión nacional que se propone representa la puerilidad que aparenta la Teletón, en su lenguaje para niños y niños-adultos, la cual pretende anular el debate político y la posibilidad de coexistir en la diferencia. En la actualidad, la unidad como parte importante de la identidad nacional y el "desafío" de la sociedad entera ya son indisociables, usando este recurso en todas sus campañas comunicacionales. Por ejemplo, en 2012 el himno oficial versa: “y vamos Chile, falta muy poco, si ellos no se rinden nosotros tampoco [...] puro corazón, es la Teletón [..] demuestra tu amor, es por los niños de mi lindo país" (himno "Puro corazón"). En el videoclip, un cantante de moda

7 Pueblo originario de Chile. 
recorre sectores populares emblemáticos de la capital chilena (epor ejemplo, La Vega, las micros ${ }^{8}$, los centros comerciales, calles del casco histórico de Santiago, etcétera); también aparecen personajes tradicionales, como los chinchineros y parejas bailando cueca (baile nacional).

\section{Acción}

Así como se conmueve y se habla de unión, corazón, fraternidad, hermandad, etcétera, se pasan los avisos comerciales: "Piense cuánto puede ayudar con solo consumir Néctar papaya y frambuesa Andina" (Teletón-Cocacola, 1980). O bien, como se observa en el comercial de Almacenes París en 1982:

[Kreutzberger]: "Esta es la última semana de Teletón, por eso ahora más que nunca Almacenes París tiene ofertas increíbles para que gane usted y ayude a la Teletón". [Voz en off]: "Solera escocesa con vuelos \$1.490. Bikini variados modelos \$ 850". [Kreutzberger]: "Así se ayuda a Teletón". [Voz en off]: Juego de copas de veinticuatro piezas \$1.490". [Kreutzberger]: "Última semana de Teletón, venga a Almacenes París, por dos motivos: la Teletón y los precios" (Teletón-Almacenes París, 1982).

De esta manera, vemos cómo tras (o durante) la sensibilización, llega el momento de actuar y para ello se orienta esa acción hacia la compra y preferencia de las marcas auspiciadoras. En la cita recién expuesta (comercial de Almacenes París) puede interpretarse como lo que Boltanski y Chiapello (2002) llaman justificaciones, tanto individuales como del bien común, como es visible en la frase: "Gane usted y ayude a la Teletón” y “[por] la Teletón y [por] los precios”. En esta relación discursiva, de manera literal, comprar en Almacenes París es igual a ayudar a un niño con discapacidad. Lo relevante es que este acto discursivo es performativo (Butler, 2010), pues, efectivamente, las marcas auspiciadoras suben sus ventas en los meses de campaña.

La relación discursiva antes expuesta, sin embargo, no queda encapsulada en los espacios comerciales del espectáculo; de hecho, no existen espacios puramente comerciales o puramente emotivos-sensibilizadores, sino que todos se funden. Por ejemplo, en la primera Teletón, el "niño símbolo", un menor de seis años con una evidente discapacidad física, aparece en brazos de don Francisco recitando todas las marcas auspiciadoras en un acto de agradecimiento: "Le doy gracias a Ace, a Costa, a Té Supremo, a Cola Cao, a dos en uno..." (Teletón, 1978). Mediante este acto el niño incorpora o encarna todo lo que la Teletón representa y propone: infancia, discapacidad, ternura, humor y la especial consideración de las marcas señaladas por parte del público.

8 Buses de transporte público de Santiago. 
Rose y Miller (2008) sostienen que ciertas prácticas publicitarias donde se fusiona psicología y marketing constituyen una economía política de la subjetivación, en la cual las tecnologías del consumo junto a formas narrativas comerciales establecen un hábitat público de imágenes. Esto sería, según los autores, una especie de pedagogías cotidianas que generan disposiciones específicas. En el caso de Chile de los años setenta y ochenta, ningún concepto podría describir tan bien la función que cumplió la Teletón en enseñar una nueva manera de sentir y actuar. Concretamente, en la década de 1980 las relaciones discursivas que vinculan caridad y mercado eran totalmente novedosas en Chile.

Un ejemplo que ilustra la pedagogía cultural que acompañó a las reformas neoliberales es la presentación en público de las Administradoras de Fondos de Pensión (AFP's), una consecuencia de la reforma previsional de 1981. Las AFP's eran un modelo previsional absolutamente nuevo y, por consiguiente, necesitaban darse a conocer y despejar cualquier atisbo de desconfianza que pudiese haber en torno a este nuevo modelo. A modo de ejemplo, se expone la narración de una pieza audiovisual de la AFP Provida publicitada en la Teletón en 1981.

Cada vez que el sol surge anunciando una nueva jornada, el país reanuda sus buenos propósitos desarrollando todo su vigor. Con esa misma energía creadora, la reforma previsional, que es la transformación social más importante de 1981, se convierte en la semilla más pródiga, donde en el presente se siembra la tranquilidad para un futuro de total plenitud. Esta es la filosofía vital y colmada de esperanzas que practica Provida, la nueva previsión, y es la primera, por la solidez de los accionistas que promovieron su creación. Primera, por el trato personalizado y el excelente servicio que presta en sus setenta oficinas a lo largo de todo el país. Primera, por el medio millón de personas que nos dieron su confianza afiliándose a Provida. Por todas estas pruebas que confirman su seguridad, Provida abrió los brazos invitando a los afiliados de todas las otras AFP's, a participar en los concursos y acontecimientos de la gran familia Provida. Provida entrega hoy este avión- ambulancia a la cuarta Teletón, como un aporte para que esta hermosa obra chilena, pueda llegar a los lugares más apartados del país, para ayudar a todos aquellos que lo necesitan. Y en este espíritu, Provida se identifica totalmente con la Teletón, porque es una obra de todos los chilenos y, porque la mano del hombre debe estrechar la mano del hombre. Porque nadie mejor que Provida puede entender el lema que identifica a la Teletón. Juntos, todo es posible (Teletón-Provida, 1981).

En este ejemplo vemos cómo la reforma al sistema previsional era publicitada en asociación directa al prestigio de la Teletón; y, asimismo, en el transcurso del programa se vincula a esta AFP a la unión nacional.

Como se observa, los productores del espectáculo usaron este espacio privilegiado por su prestigio, cobertura y duración, para traspasar esa 
confianza al nuevo sistema de pensiones. El llamado a ayudar mediante el consumo personal ha continuado hasta el presente. Por ejemplo, en 2011, en un aviso comercial del supermercado Unimarc, se muestra a don Francisco en una de las sucursales anunciando: "Hoy los esperamos en todos los Unimarc a lo largo de Chile, para que nos ayuden a cumplir nuestro desafío. Prefiere Unimarc, porque tu compra es una sonrisa para los niños de la Teletón..." (Unimarc- Teletón, 2011). Mientras tanto, una veintena de consumidores circulan tras el protagonista con carros de supermercado llenos de globos en forma de corazones rojos o llevando estos en sus manos. Esto es un caso concreto de la capacidad de la televisión como medio index (Martín-Serrano, 2008), donde se invoca una práctica (ayude comprando), se indexa a una imagen (consumidores acarreando corazones) y, al mismo tiempo, se asocia a una marca (Teletón) que contiene potentes mensajes sociales.

\section{Naturalización}

Cada año, el o la presidenta de la República en turno, sin importar el sector político, asiste al espectáculo televisivo en momentos clave (obertura o cierre), en ocasiones aportando el cheque del Estado. Esta donación de fondos públicos, que también ocurre mediante las gobernaciones regionales y otros de salud, emplazan al Estado como una empresa privada más que participa haciendo donaciones. Esto es, al menos, problemático en una sociedad neoliberal como la chilena, en la cual se promueve una noción de Estado que actúa al margen de las actividades del mercado. Como se puede observar, el Estado no solo apoya, sino que es un promotor activo y financia las actividades del mercado (en este caso, de manera visible en la Teletón), al mismo tiempo que se economiza la gestión de la rehabilitación infantil. Adicionalmente y en consecuencia, el modelo social de la discapacidad (Barton, 2008; Ferreira, 2008) o uno de enfoque de derechos ${ }^{9}$ quedan de facto excluidos. En el transcurso del tiempo todas estas formas de convivir y gestionar "lo social" se han ido naturalizando en la sociedad chilena.

La Teletón es parte de la cultura y de un sentir nacional. Más aún, en Chile se dice que los chilenos "somos chilenos campeones mundiales de la solidaridad, del amor de la esperanza de la rehabilitación” (Rodrigo Cáceres, a veinte años de haber sido "niño símbolo", en Bontempi, 2012). Los chilenos como "campeones mundiales de la solidaridad" ha pasado a ser una consigna que se repite ya no solo a partir de la Teletón, sino en otras situaciones que

9 De manera contradictoria, pues, como señala Ferrante (2017), hace aproximadamente una década Chile adoptó (en la formalidad) un enfoque de derechos. 
se comparten a través de la televisión, como la tragedia tras un terremoto, maremoto, una ola de incendios o un accidente minero. ${ }^{10}$ De este modo, la Teletón y su modelo de sentir-actuar permea la cultura chilena y su identidad de manera significativa.

\section{Limitaciones}

Una de las limitaciones de esta investigación es la unilateralidad de su muestra; si bien se ha dicho que televisión y cultura se producen mutuamente, solo se ha analizado los discursos que se producen de la Teletón, sin considerar cómo la población recibe estos mensajes, además de que subvierte, modifica o rechaza lo que propone la televisión. Los estudios en el campo de la comunicación han demostrado, hace varias décadas, que los efectos de la comunicación no son unilaterales y dependen en gran medida de la recepción y la apropiación de los contenidos por parte de la audiencia.

Así, a pesar de que la Cuarta Encuesta Nacional de Opinión Pública (ICSO-UDP, 2008) y la investigación de Ferrante (2017) dan cuenta de la recepción de este espectáculo, podrían realizarse otros estudios para profundizar en las interpretaciones de la audiencia y para analizar el desenvolvimiento de la Teletón en las diversas naciones de la región. Por último, cabe señalar que el modelo medicalizado de la discapacidad del cual la Teletón es cómplice y promotor activo, así como las consecuencias para los niños y para las personas con discapacidad, ha sido analizado en otro lugar (Humeres, 2017), por lo que a pesar de su relevancia, en este artículo son aspectos que se incorporan de manera tangencial.

\section{Conclusiones}

Mediante los tres momentos: sensibilización, identificación y acción, he querido mostrar el mecanismo persuasivo mediante el cual la Teletón funciona y se involucra en la cultura nacional. Junto a la Teletón y su enorme despliegue en el tiempo y espacio, en la actualidad se ha naturalizado un modelo de discapacidad y de resolver el bienestar social, así como el individual, en medio de un vacío de seguridad social y estándares de garantías mínimas para las personas con discapacidad, y un enfoque de derechos deficitario.

De esta manera, el espectáculo televisivo es efectivo y existe condiciéndose con una estructura social que opera bajo las mismas pautas, pues la 10 Como cuando, en 2010,33 mineros quedaron atrapados bajo 720 metros de profundidad y fueron rescatados tras 70 días. 
Teletón es un ejemplo de intermediación entre instituciones, regulaciones y cuarenta años de política neoliberal. Por consiguiente, a pesar de que hoy en día las nuevas tecnologías de la comunicación han reconfigurado el lugar de la televisión en la sociedad, el poder mediador de esta aún no puede ser desestimado.

El caso, puesto en su perspectiva histórica y contextual, también permite ver el modelo comunicacional como parte de una pedagogía social funcional a la transformación de la sociedad socialista en una neoliberal. La coyuntura tecnológica (expansión de la televisión en el territorio) junto a la coyuntura política (dictadura, violencia y reformas al sistema de salud, previsionales, privatización de la televisión pública) hicieron posible la Teletón como modelo. En el caso estudiado se aprecian cómo se vinculan las justificaciones individuales con unas, que podrían llamarse, del bien colectivo en el contexto de una sociedad de individuos sin seguridad social colectiva.

Sin embargo, de cierto modo la explicación de las justificaciones, como argumentación racional, se opone a la visión de los mecanismos gubernamentales. Como se vio, en la Teletón operan diversas estrategias, emociones, discursos y acciones que van mucho más allá de una justificación racional. Por lo tanto, el modo en que funciona la Teletón puede ser mejor comprendido desde la gubernamentalidad o el arte de gobernar a la distancia, mediante los deseos, que desde el enfoque de Boltanski y Chiapello (2002). Con todo, esto no implica necesariamente descartar este último enfoque del todo, pudiendo ser considerado como una variable más.

Más allá de la abstracción de los tres momentos que he propuesto, la gubernamentalidad neoliberal, sin duda, es más compleja. Gobernar a la distancia o establecer una conducta de la conducta (Foucault, 2007) va de la mano con mecanismos que son tan discursivos como estructurales, tan simbólicos como materiales. Por una parte, a nivel discursivo, la acción se estimuló: suministrando nuevas relaciones discursivas ("rehabilitación emocional”), difundiendo las nuevas definiciones (ejemplo, soluciones de mercado a problemas sociales), estructurando juicios morales (el esfuerzo individual es fundamental para superarse y mediante la promoción de modos de acción ("ofertas increíbles para que gane usted y ayude a la Teletón"). Con todo, por más discursivos o simbólicos que sean, tanto los componentes emocionales como de identidad son parte de la acción política. Tal como explica Larraín (2001), las identidades nacionales generan sentimientos de lealtad, comunidad, fraternidad, siendo capaces de movilizar grandes masas. Así, la identidad nacional es también un proceso político que trae consecuencias concretas en el destino de la nación. 
Finalmente, un análisis de la gubernamentalidad neoliberal a la luz de las investigaciones de Mirowski y Plehwe (2009) y Foucault (2007), en relación con el caso analizado, permite destacar al menos dos características del neoliberalismo: el papel activo del Estado en la estructuración del modelo social de mercado, y la modelación de todas las áreas de la vida según los principios del mercado. Dos cuestiones que son diferentes de las sociedades liberales o "liberales avanzadas" (Rose, 1993) como las europeas, motivo por el cual los casos de gubernamentalidad latinoamericana deberían considerar críticamente los análisis europeos en atención a sus propias particularidades. Como se vio, lejos abstenerse, el Estado patrocina modelos como el de la Teletón bajo una aparente neutralidad política, al mismo tiempo que promueve un tipo de modelo social, el neoliberal.

\section{Referencias}

Barton, Len (2008), Superar las barreras de la discapacidad, España: Ediciones Morata.

Boas, Taylor y Gans-Morse, Jordan (2009), "Neoliberalism: From new liberal philosophy to anti-liberal slogan”, en Studies in Comparative International Development, año 44, núm. 2, Alemania: Springer.

Boltanski, Luc y Chiapello, Eve (2002), El nuevo espiritu del capitalismo, España: Akal.

Bontempi, Rossana (2012), La Telemaratón de Jerry Lewis / Origen de la Teletón Chilena. [documental de Canal 13], Chile. Disponible en: https://www.youtube.com/ watch?v=Jp6uUWpUUmY [15 de junio de 2018].

Brady, Michelle (2016): "Governing practices: Neoliberalism, governmentality, and the ethnographic imaginary", en Brady, Michelle y Randy, Lippert [eds.], Governing practices: Neoliberalism, governmentality, and the ethnographic imaginary, Canadá: University of Toronto Press.

Butler, Judith (2010), "Performative agency", en Journal of Cultural Economy, año 3, núm. 2, Reino Unido: Taylor \& Francis.

Callon, Michel (1986), "Some elements of a sociology of translation: domestication of the scallops and the fisherman of St Brieuc bay", en Law, John [ed.], Power, action and belief: a new sociology of knowledge, Inglaterra: Routledge.

Cavallo, Ascanio (1989), La Historia Oculta del Régimen Militar: Memoria de una época 1973-1988, Chile: Uqbar Editores.

Correa, Sofía et al. (2001), Historia del siglo XX chileno, Chile: Sudamericana.

Cuevas, Hernán (2008), "La cuestión de la identidad chilena", en Percepciones y actitudes sociales $4^{\circ}$. Informe de Encuesta Nacional ICSO-UDP, Chile: Universidad Diego Portales.

Dean, Mitchell (2014), "Rethinking neoliberalism", en Journal of Sociology, año 50, núm. 2, Reino Unido: Sage.

Durán, Sergio (2012), Rie cuando todos estén tristes. El entretenimiento televisivo bajo la dictadura de Pinochet, Chile: LOM. 
Energici, Alejandra (2014), La construcción de la solidaridad como una politica neoliberal de la subjetividad: análisis de la publicidad solidaria en Chile [tesis], Chile: Universidad Alberto Hurtado.

Ferrante, Carolina (2017), "El éxito de la Teletón en Chile: paradoja y mensaje en la era de los derechos”, en Oteaiken, Boletín sobre prácticas y acción colectiva, núm. 23, Argentina: Programa de Estudios de Acción Colectiva y Conflicto Social.

Ferrante, Carolina (2018a), "Discapacidad, políticas y ¿cambio de paradigma?: Reflexión a partir del caso de personas con deficiencias físicas que piden limosna en el norte de Chile", en Trabajo y Sociedad, núm. 30, Argentina: Universidad Nacional de Santiago del Estero.

Ferrante, Carolina (2018b), “Machetear': Surviving disability through mendicity in the North of Chile", en European Journal of Disability Research, núm. 12, Francia: Elsevier.

Ferreira, Miguel (2008), "Una aproximación sociológica a la discapacidad desde el modelo social: apuntes caracterológicos”, en Reis. Revista Española de Investigaciones Sociológicas, España: Centro de Investigaciones Sociológicas (CIS).

Ffrench-Davis, Ricardo (2003), Entre el neoliberalismo y el crecimiento con equidad. Tres décadas de politica económica en Chile, Chile: LOM.

Fischer, Ronald y Serra, Pablo (2004), Efectos de la privatización de servicios públicos en Chile: Casos sanitario, electricidad y telecomunicaciones, Chile: Inter-American Development Bank.

Flew, Terry (2014), "Six theories of neoliberalism”, en Thesis Eleven, núm. 122, Reino Unido: Sage.

Foucault, Michel (2007), Nacimiento de la biopolitica. Curso en el College de France: 19781979, Argentina: Fondo de Cultura Económica.

Foucault, Michel (2003), Historia de la sexualidad, vol. I: La voluntad de saber, España: Siglo XXI.

Fougère, Martin (2010), "Governmentality”, en Mills, A. et al. [eds.] (2010), Encyclopedia of Case Study Research, vol. 4, núm. 1, Reino Unido: Sage.

Fundación Teletón (2013), Somos en Teletón, Chile. Disponible en: www.teleton.cl [13 de enero de 2013].

Gane, Nicholas (2014), "Sociology and neoliberalism: A missing history”, en Sociology, año 48, núm. 6, Reino Unido: Sage.

Gárate, Manuel (2012), La revolución capitalista de Chile, Chile: Universidad Alberto Hurtado.

Grandes Marcas (2019), Hall of Fame, Chile. Disponible en: https://grandesmarcas.cl/hallof-fame/ [05 de mayo de 2019].

Gutiérrez, Pamela (2014), "Cuerpo, discapacidad y prácticas institucionales: Una vision crítica de su evolución histórica en Chile”, en Revista Chilena de Terapia Ocupacional, año 14, núm. 2, Chile: Universidad de Chile.

Guzmán, Virginia et al. (2017), "Legitimación y crítica a la desigualdad: una aproximación pragmática”, en Convergencia. Revista de Ciencias Sociales, año 24, núm. 73, México: Universidad Autónoma del Estado de México.

Hall, Stuart (1973), Encoding and decoding in the television discourse, Reino Unido: University of Birmingham.

Hamilton, Mary (2011), "Unruly practices: What a sociology of translations can offer to educational policy analysis", en Educational Philosophy and Theory, núm. 43, Reino Unido: Blackwell Publishing. 
Mónica Humeres. "Gane usted y ayude a la Teletón": mecanismos neoliberales en la gestión del bienestar

Harvey, David (2005), A Brief History of Neoliberalism, Estados Unidos: Oxford University. Hirschman, Albert (1977), The Passions and the Interests: Political Arguments for Capitalism before its Triumph, Estados Unidos: Princeton University Press.

Humeres, Mónica (2017), "Hacia una genealogía del 'niño símbolo”, en Pavez, J. [coord.] (2017), (Des) Orden de Género. Politicas y mercados del cuerpo en Chile, Chile: CRANN Editores.

Illouz, Eva (2007), Intimidades congeladas: las emociones en el capitalismo, Argentina: Katz Editores.

ICSO [Instituto de Investigación en Ciencias Sociales] y UDP [Universidad Diego Portales] (2008) Cuarta Encuesta Nacional de Opinión Pública. Disponible en: http://www. encuesta.udp.cl/descargas/enc2008/informe.pdf [05 de junio de 2019].

Klein, Naomi (2007), The Shock Doctrine: The rise of disaster capitalism, Estados Unidos: Metropolitan Books, Henry Holt and Company.

Larraín, Jorge (2001), Identidad Chilena, Chile: LOM.

Lasswell, Harold (1927), Propaganda technique in the world war, Estados Unidos: MIT Press.

Lee, Stephanie (2008), “What is neo-liberalism?”, en Socio-economic Review, año 6, núm. 4, Reino Unido: Oxford University Press.

Leighton, Pablo (2012), "Televisión + estado de sitio: la perentoria doble cadena del golpe en Chile”, en Pincheira, I. [ed.], Archivos de Frontera: El Gobierno de las Emociones en Argentina y Chile del Presente, Chile: Ediciones Escaparate.

Lemke, Thomas (2012), "Foucault, governmentality, and critique", en Rethinking marxism, año 14, núm. 3, Reino Unido: Taylor \& Francis.

Martín-Serrano, Manuel (2008), La mediación social, España: Akal.

Mirowski, Philip (2009), "Defining Neoliberalism (postfacio)” en Mirowski, P., y Plehwe, D. [eds.] (2009), The road from mont Pelerin: The making of the neoliberal thought collective, with a new preface, Estados Unidos: Harvard University Press.

Mirowski, Philip y Plehwe, Dieter [eds.] (2009), The road from mont Pèlerin: The making of the neoliberal thought collective, Estados Unidos: Harvard University Press.

Peck, Jamie et al. (2010), "Postneoliberalism and its malcontents", en Antipode: A Radical Journal of Geography, núm. 41, Reino Unido: Wiley Blackwell.

Plehwe, Dieter (2009), "Introduction", en Mirowski, P. y Plehwe, D. [eds.] (2009), The road from mont Pelerin: The making of the neoliberal thought collective, Estados Unidos: Harvard University Press.

Riessman, Catherine (2008), Narrative methods for the human sciences, Estados Unidos: Sage.

Román-Brugnoli, José et al. (2014), "Solidaridad en el debate global y local: reflexión desde un análisis del caso chileno”, en Convergencia. Revista de Ciencias Sociales, año 21, núm. 66, México: Universidad Autónoma del Estado de México.

Rose, Nikolas (1993), “Government, authority and expertise in advanced liberalism”, en Economy and Society, año 22, núm. 3, Reino Unido: Taylor \& Francis.

Rose, Nikolas y Miller, Peter (1992), "Political Power beyond the State: Problematics of Government", en British Journal of Sociology, año 43, núm. 2, Reino Unido: Wiley Blackwell for the London School of Economics.

Rose, Nikolas y Miller, Peter (2008), "Mobilizing the consumer", en Theory, Culture \& Society, año 14, núm. 1, Reino Unido: Sage.

Sierra, Lucas (2006), Hacia la televisión digital en Chile. Historia y transición, Chile: Centro de Estudios Públicos. 
Silva, Patricio (1995), "Empresarios, neoliberalismo y transición democrática en Chile", en Revista Mexicana de Sociología, año 57, núm. 4, México: Universidad Nacional Autónoma de México.

Tagle, Matías (2009), “Los primeros 50 años de la Televisión Chilena”, en Historia, año 42, núm. 1, Chile: Pontificia Universidad Católica de Chile.

Teletón (1978), Primera Teletón. Disponible en: https://www.youtube.com/ watch?v=SNkODjDg73w [05 de mayo de 2019].

Teletón (2019), Hall of Fame Chile en Grandes Marcas, Chile. Disponible en: https:// grandesmarcas.cl/hall-of-fame/teleton/ [05 de junio de 2019].

Teletón-Almacenes París (1982), Ofertas Increíbles. Disponible en: https://www.youtube. com/watch?v=HdPY_iutCxo [05 de junio de 2019].

Teletón-Cocacola (1980), Comercial Néctar Andina. Disponible en: https://www.youtube. $\mathrm{com} /$ watch?v=TK7dzjOvx6k [05 de junio de 2019].

Teletón-Provida (1981), Avión Ambulancia. Disponible en: http://www.youtube.com/ watch?v=dCN6bF-BhBY [05 de junio de 2019].

Teletón-Unimarc (2011), Guatita llena corazón contento. Disponible en: https://www. youtube.com/watch?v=sTE1XHpsXsI [05 de junio de 2019].

Thorsen, Dag Einar (2010), "The Neoliberal Challenge-What is Neoliberalism", en Contemporary Readings in Law and Social Justice, año 2, núm. 2, Noruega: University of Oslo.

Undurraga, Tomás (2014), Divergencias: trayectorias del neoliberalismo en Argentina y Chile, Chile: Universidad Diego Portales.

Ureta, Sebastián (2015), Assembling Policy: Transantiago, Human Devices, and the Dream of a World-class Society, Estados Unidos: The MIT Press.

Valdés, Juan Gabriel (1995), Pinochet's Economists: The Chicago School in Chile, Reino Unido: Cambridge University Press.

Weber, Max (2001), La ética protestante y el espiritu del capitalismo, España: Alianza.

Zondek, Andrea et al. (2004), Primer Estudio Nacional de la Discapacidad en Chile, Chile: Fondo Nacional de Discapacidad, Gobierno de Chile.

Mónica Humeres. Candidata a Doctora en Sociología, Universidad Alberto Hurtado. Becaria de la Comisión Nacional de Ciencia y Tecnología (Conicyt) Chile. Líneas de investigación: sociología de la comunicación, estudios de ciencia, tecnología y sociedad, políticas públicas. Publicaciones recientes: Humeres, Mónica (2018), "Crítica a las genealogías reales e imaginarias", en Cinta de moebio, Revista de Epistemología de Ciencias Sociales, núm. 63, Chile: Universidad de Chile; Cienfuegos, Javiera, Moreno, Cecilia y Humeres, Mónica (2017), “¿Puede un hombre ser carga de una mujer?”, en Vera, A. [ed.], Malestar Social y Desigualdades en Chile, Chile: Universidad Alberto Hurtado; Humeres, M. (2017), "Hacia una genealogía del 'niño símbolo"”, en Pavez, J. [coord.] (Des) Orden de Género. Politicas y mercados del cuerpo en Chile, Chile: CRANN Editores. 